\title{
ОНТОЛОГИЧЕСКИЕ СЦЕНАРИИ ПЕРЕПОДГОТОВКИ ПРАКТИКУЮЩИХ ВРАЧЕЙ
}

\author{
А. Е. Стрижак, О. П. Минцер', С. В. Денисенко' \\ Национальный центр «Малая академия наук Украины» \\ Национальная медицинская академия последипломного образования \\ имени П. Л. Шупика'
}

Постановка проблемы. Современные достижения компьютерных наук в сфере образования привели к совместному использованию данных во многих различных хранилищах. Использование информационно-коммуникационных технологий (ИКТ) является условием обеспечения новаторской альтернативы традиционному обучению, создавая возможности для персонального обучения, интерактивных занятий и коллективной работы в компьютерной сети независимо от местоположения ученика. Мир становится цифровым, а его жители должны обладать цифровыми технологиями и использовать их эффективно в различных отраслях экономики, включая и образование и науку, и бизнес. В таких условиях ключевым моментом является доступ к информационным источникам формирования знаний, размещаемых в соответствующих средах и могут быть доступны из любого места и в любое время [8].

Сейчас при разработке корпоративных систем управления информационными источниками проблематична задача - не программный аспект, а задача поиска, формулировки, формирования, структурирования и представления данных и сообщений, из которых в дальнейшем формируются знания. Корпоративная ИКТ-система, или просто, ИКТ-система - составляющая образовательных организационных структур (OOC), обеспечивает эффективную реализацию корпоративных ИКТ-процессов, в которой сбор и обработка данных осуществляется автоматизировано с помощью соответствующих средств компьютерной техники и ИКТ. Средства и технологии корпоративной ИКТ-системы образуют в ООС адаптивную, интегрированную информационно-образовательную среду, которая развивается и активно оказывает определяющее влияние на формирование в ООС наиболее благоприятных (информационно-комфортных) условий для эффективного осуществления его функций [1]. При этом возрастают требования к повышению производительности ИКТ, их надежности при постоянном увеличении объемов обрабатываемых данных.

Анализ исследований и публикаций. Использование программно-информационных средств ИКТ в образовательном пространстве НМАПО имени П. Л. Шупика обеспечивает построение персонифицированной корпоративной компьютерно-интегрированной учебной среды, в которой поддерживаются режимы непрерывного электронного дистанционного взаимодействия между врачами-практиками и преподавателями различных кафедр, и в частности сопровождения курса лечения. Е-дистанционное обучение - разновидность дистанционного обучения, по которым участники и организаторы учебного процесса осуществляют преимущественно индивидуализированные взаимодействия как асинхронно, так и синхронно во времени, преимущественно и принципиально используя электронные транспортные системы снабжения учебных материалов и других информационных объектов, компьютерные сети Интернет / Интранет, ИКТ [3]. Одной из задач деятельности в этой среде является предоставление условий эффективного использования информационных ресурсов всеми участниками учебного процесса в медицинском учреждении - освоение врачами новых знаний в области их лечебной практики. Для этого создаются средства формализации учебных информационных источников формирования знаний, учитывающие специфику лечебного процесса. С помощью программно-информационных компонентов ИКТ обеспечивается создание и использование баз учебных и научных источников, на основе которых реализуется образовательный процесс для конкретной личности. При использовании программноинформационных средств ИКТ в лечебной практике врача был учтен тот факт, что объем и разнообразие данных и сообщений по различным профилям медицинских знаний ныне настолько объемны, что возникает необходимость их классификации с точки зрения принадлежности к предметным областям или сферам интересов всех участников учебного процесса в области медицинской и лечебной практики. И речь идет не только о данных, хранящихся в специализированных базах или информационных хранилищах, но и о динамических сообщениях, генерируемых определенными источника-

() А. Е. Стрижак, О. П. Минцер, С. В. Денисенко 
ми при необходимости. Применение этих программно-информационных средств ИКТ ориентировано на решение следующих задач:

- обеспечение возможности оперативной организации доступа к информационным источникам формирования знаний, касающихся одной предметной области или объединенных схожими интересами сфер деятельности;

- поддержание взаимодействия всех участников учебного процесса в рамках неединичного множества предметных областей с возможностью расширения этого множества;

- обеспечение возможности расширения списка источников и потребителей разнородных информационных источников формирования знаний в рамках определенной предметной области или сферы интересов;

- ограничение доступа к информационным ресурсам учебного назначения рамками конкретной предметной области или сферы интересов в связи с возможностью решения предыдущей задачи;

- обеспечение возможности для каждого субъекта образовательного процесса использования информационных ресурсов учебного назначения нескольких предметных областей,

- обеспечение возможности оперативного поиска обучаемыми источника необходимых информационных ресурсов, касающейся конкретной предметной области [7].

Онтологический подход к проектированию персонифицированных корпоративных ИКТ-систем как раз и позволяет создавать системы, в которых информационные источники формирования знаний становятся доступными для всех участников учебного процесса. Основные преимущества этого подхода:

- онтологический подход предоставляет пользователю целостный, системный взгляд на определенную предметную область;

• информационные источники о предметной области представлены однотипно, что упрощает их восприятие;

- построение онтологии позволяет восстановить недостающие логические связи предметной области.

К онтологическим аспектам относится круг вопросов, начиная от сферы применения и к формальному описанию компонентов компьютерных онтологий предметных областей. На формальном уровне онтология - система, состоящая из множества терминов, утверждений об этих понятиях, на основе которых можно строить классы, объекты, связи, функции и теории. Компьютерную онтологию некоторой предметной дисциплины можно рассматривать как общезначимую, открытую базу информационных источников формирования знаний, представленную общепринятым (формальным) языком спецификации. В онтолого-классификационной схеме средств и методов искусственного интеллекта онтологический подход трактуется как разновидность системного подхода, основанного на формировании знаний. Онтологический подход обеспечивает эффективное проектирование компонентов любой знаниеориентированной информационной системы $[5,9,10]$.

Практически все модели онтологии содержат определенные концепты (понятия, классы), свойства концептов (атрибуты, роли), отношения между концептами (зависимости, функции) и дополнительные ограничения, которые определяются аксиомами. Концептом может быть описание задачи, функции, действия, стратегии, процесса рассуждения, ход осуществления исследования и т.д. [3]. При этом внимание направлено на формализацию этапов построения, структурирования и представления информационных источников формирования знаний, позволяет учащимся эффективно усваивать лекционный материал в сочетании с практическими и лабораторными заданиями. В свою очередь, эффективная реализация указанных этапов и получения конечного результата (библиотеки онтологических баз информационных источников формирования знаний) невозможна без проведения системно-онтологического анализа заданной совокупности информационных учебных ресурсов [4].

Один из подходов, который обеспечит эффективное функционирование такой системы - это построение онтологической модели е-сценария сопровождения процесса лечения. Е-сценарий сопровождения лечебного процесса - это система формализации с помощью онтологического подхода ее построения, операционально, пошагово воспроизводит маршрут подготовки и проведения курса лечения с использованием различных средств интернет-технологий и программных модулей (сетевые электронные научные и учебно-методические ресурсы, базы данных, сервисно-функциональные и аналитические программные модули и т.д.), которые формируются заданной областью и множеством целей лечебного курса. Эти ресурсы не только существенно разнообразят содержательную составляющую е-методических систем поддержки учебной деятельности, но и учитывают специфику реализации всего процесса обучения [2].

Процесс формирования онтологической модели е-сценария сопровождения процесса курса лечения 
состоит в том, что имея описание определенных понятий, можно согласованно представлять их в виде объектов средствами построения онтологии [7]. Для визуализации создания онтологических моделей может быть использована компьютерная программа «Графедитор». Исходными данными для программы «Графедитор» являются описания объектов, представленные множеством их признаков. Исходные данные могут быть представлены в виде текстового файла. Структура текстового файла следующая:

(Имя объекта 1) ..., (имя признака n)

(Имя объекта 2) ... (имя признака ј)

(Имя объекта m) ... (имя признака k).

Онтологическая модель сопровождения процесса курса лечения (е-сценарий) была создана с помощью вышеуказанного компьютерного средства.
Общая формула формализации этой онтологической модели: $\mathrm{S}=\{\mathrm{Oa}\{\mathrm{Pb}\{\mathrm{Td}\{\mathrm{Ee}\{\mathrm{Cq}\{\mathrm{Mv}\{\mathrm{Zg}\} \mathrm{Rh}$ $\{\mathrm{Zg}\}\}\}\}\}\}\}$, где

- Субъекты лечебного курса: $\mathrm{B}=\{\mathrm{Oa}\}, \mathrm{a}=1,2,3, \ldots . \mathrm{m}$;

- Системы организма лечебного курса: $\mathrm{P}=\{\mathrm{Oa}$ $\{\mathrm{Pb}\}\} \mathrm{b}=\mathrm{a} 1, \mathrm{a} 2, \mathrm{a} 3, \ldots . ., \mathrm{An}$;

- Диагнозы лечебного курса: $\mathrm{T}=\{\mathrm{Pb}\{\mathrm{Td}\}\} \mathrm{d}=\mathrm{b} 1$, b2, b3, ...., Bn;

-Этапы лечебного курса: $\mathrm{E}=\{\mathrm{Td}\{\mathrm{Ee}\}\} \mathrm{e}=\mathrm{d} 1, \mathrm{~d} 2$, $\mathrm{d} 3, \ldots . ., \mathrm{Dn}$;

- Цель лечебного курса: $\mathrm{C}=\{\mathrm{Ee}\{\mathrm{Cq}\}\} \mathrm{q}=\mathrm{e} 1, \mathrm{e} 2$, e3, ...., En;

- Средства лечебного курса: $Z=\{\mathrm{Cq}\{\mathrm{Zg}\}\} \mathrm{g}=\mathrm{q} 1$, q2, q3, ...., Qn;

- Маршрут лечебного курса: $\mathrm{M}=\{\mathrm{Cq}\{\mathrm{Mv}\{\mathrm{Zg}\}\}\}$, $\mathrm{v}=\mathrm{g} 1, \mathrm{~g} 2, \mathrm{~g} 3, \ldots . ., \mathrm{Gn} ;$

- Оценка результатов: $\mathrm{R}=\{\mathrm{Cq}\{\mathrm{Rh}\{\mathrm{Zg}\}\}\} \mathrm{h}=\mathrm{v} 1$, v2, v3, ...., Hn.

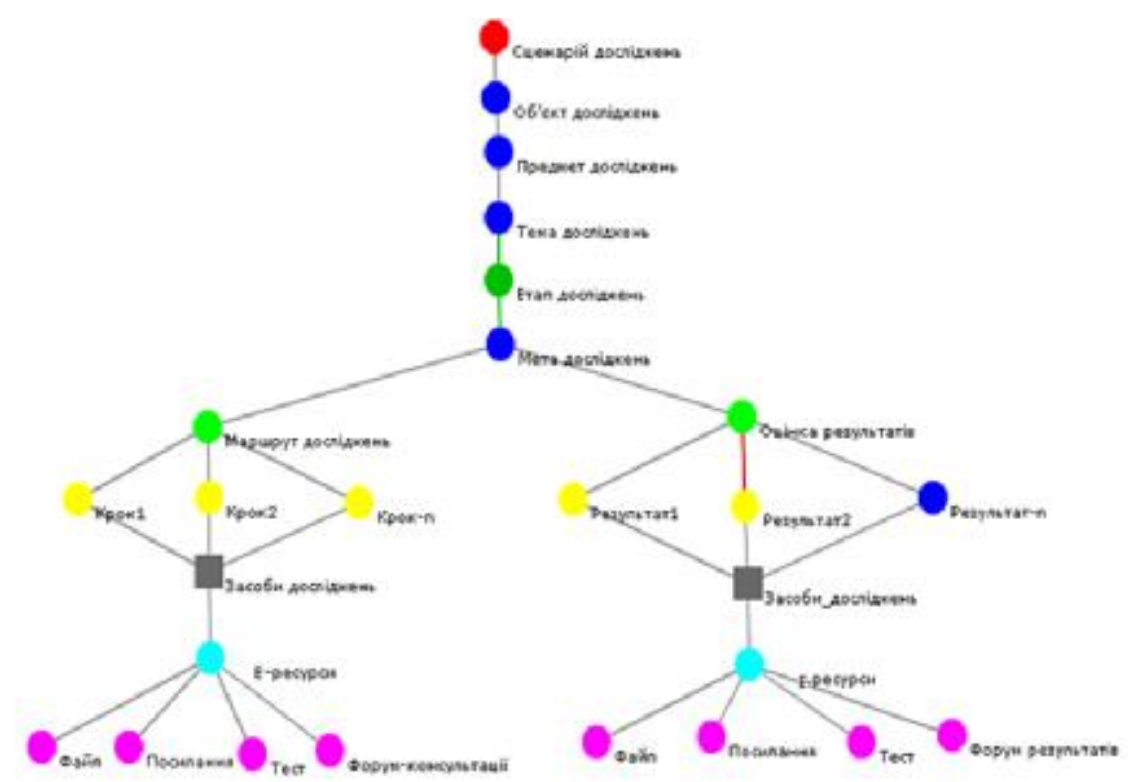

Puc. 1. Общая граф-ориентированная структура онтологической модели е-сценария сопровождения учебного процесса по изучению новой методики лечения врачами.

Выводы. Одним из перспективных направлений дальнейшего совершенствования персонифицированных корпоративных ИКТ-систем - составляющих образовательных организационных структур, является разработка методологических, онтологических и логических основ конструирования баз информационных источников формирования знаний. Онтологии играют решающую роль в модели описания формирования таких систем. Это предполагает решение актуальных проблем повышения эффективности переподготовки врачей на основе применения современных сетевых технологий е-дистанционного доступа к распределенным системам формирования знаний. Одной из задач является создание онтологических описаний и моделирования событий, которые определяют курс лечения. Использование предложенного метода построения онтологической модели е-сценария сопровождения лечебного процесса позволяет разнообразить этот процесс и сделать его более персонифицированным. Это достигается за счет того, что врач имеет возможность использовать свой собственный опыт, строить свои модели формирования знаний. 


\section{Литература.}

1. Биков В. Ю. Електронна педагогіка та сучасні інструменти систем відкритої освіти [Електронний ресурс] / В. Ю. Биков, І. В. Мушка// Інформаційні технології і засоби навчання. - 2009. - № 5(13). - Режим доступу до журналу : http://www.ime.edu-ua.net/em.html.

2. Биков В. Ю. Моделі організаційних систем відкритої освіти : Монографія [Текст] / В. Ю. Биков .-К. : Атіка, 2008 .684 с. : іл.

3. Гладун А. Я. Онтологии в корпоративных сетях [Электронный ресурс] / А. Я. Гладун, Ю. В. Рогушина // Интернет-журнал «Корпоративные информационные системы», 2006. - № 1. - Режим доступа : http:// www.management.com.ua/ims/ims $115 . \mathrm{html}$.

4. Дем'яненко В. Б. Комп'ютерні онтології-технологічна основа формування освітянських інформаційних ресурсів [Електронний ресурс] / В. Б. Дем'яненко, О. Є. Стрижак // Інформаційні технології і засоби навчання. - 2011. - Том 22. - № 2. - Режим доступу до журналу : http:// journal.iitta.gov.ua/index.php/itlt/article/view/419.

5. Стрижак О. С. Інформаційно-технологічні рішення формування операційного простору діяльності обдарованої особистості [Електронний ресурс] / [Г. Востров, С. Кальной, О. Павлов та ін.]. - Режим доступу : http:// archive.nbuv.gov.ua/portal/Soc_Gum/Nivoo/2010_4/22.pdf.
6. Мананникова Н. Н. Учебно-исследовательская работа учащихся : методические рекомендации для учащихся и педагогов [Электронный ресурс] / Н. Н. Мананникова. Web-сайт. Социальная сеть работниковобразования nsportal.ru. - Режим доступа : http://nsportal.ru/blog/shkola/ obshcheshkolnaya-tematika/nauchno-issledovatelskayarabota-uchashchikhsya.

7. Применение методов и средств онтологического анализа для управления образовательной деятельностью [Текст] / В. В. Мартынов, В. И. Рыков, Е. И. Филосова, Ю. В. Шаронова // Вестник УГАТУ. Управление в социальных и экономических системах. - Уфа: УГАТУ, 2012. - Т. 16. - № 3 (48). -C. 230-234.

8. Палагин А. В. К проектированию онтологоуправляемой информационной системы с обработкой естественно-языковых объектов [Текст] / А. В. Палагин, Н. Г. Петренко // Математические машины и системы, 2008. -№ 2. - С.14-23. 9. Стрижак О. С. Комп'ютерні тезауруси як технологічна платформа створення авторських методик викладання предметних дисциплін [Текст] / О. С. Стрижак // Актуальні проблеми психології : Психологічна теорія і технологія навчання / за ред. С. М Максименко, М. Л. Смульсон. - К. : Вид-во НПУ імені М. П. Драгоманова, 2009. - Т.8. - Вип.6. - С. 259266. 